\title{
Acquaintance, approach and application of pharmacovigilance: questionnaire based study at a tertiary care teaching hospital in Dhaka
}

\author{
Morshed Nasir*, Tahmina Zahan, Nadia Farha, A. S. M. Salauddin Chowdhury
}

Department of Pharmacology and Therapeutics, Holy Family Red Crescent Medical College, Dhaka, Bangladesh

\author{
Received: 24 July 2020 \\ Revised: 08 September 2020 \\ Accepted: 09 September 2020 \\ *Correspondence: \\ Dr. Morshed Nasir, \\ Email: morshednasir@hotmail.com
}

Copyright: () the author(s), publisher and licensee Medip Academy. This is an open-access article distributed under the terms of the Creative Commons Attribution Non-Commercial License, which permits unrestricted non-commercial use, distribution, and reproduction in any medium, provided the original work is properly cited.

\begin{abstract}
Background: Pharmacovigilance is proven as an effective monitoring mechanism for safety and efficacy of pharmaceutical products with the assistance of physicians, pharmacists, nurses, and other healthcare professionals to avoid undue physical, mental and financial suffering of patients. Thus, this study was conducted to assess awareness of pharmacovigilance among the healthcare service providers to evaluate the acquaintance, approach application (3A) of judicial reporting of ADRs and pharmacovigilance in a tertiary care teaching hospital in Dhaka.

Methods: A pre-tested questionnaire-based study was done among the 5th year medical students, interns, doctors and nurses of Holy Family Red Crescent Medical College, Dhaka, Bangladesh to assess the overall status of acquaintance (knowledge), approach (attitude) and application (practice) pharmacovigilance. Total 417 questionnaires were distributed and 389 were included as valid, compiled and analysed using SPSS version 25.0.

Results: Among the respondents, almost $78 \%$ of the nurses responded the right answers and doctors responded the lowest $29 \%$ on average. The average percentage of approach and application of pharmacovigilance was low in all the respondent groups. The poorest outcome was observed about reporting an adverse drug reactions (ADR) form by all respondents as $01 \%$ to $08 \%$.

Conclusions: The overall status of pharmacovigilance in a tertiary teaching hospital was found paradoxically low, that revealed the necessity of much more initiatives at the undergraduate and postgraduate academic curriculum and intensive motivation, training, monitoring should be addressed to ensure the safety of medication, rationality of drug use and accomplish the national pharmacovigilance programs.
\end{abstract}

Keywords: Pharmacovigilance, ADR, Rational drug use, Drug safety, ADR reporting

\section{INTRODUCTION}

Pharmacovigilance is also termed as drug safety is defined by the WHO as the study of science and activity related to collection, assessment, detection and knowledge about the long term and short term adverse effects of a drug or any other drug related problems and also the prevention of these adverse effect particularly long-term and short-term adverse effects. ${ }^{1}$ Drugs are the mainstay of treating diseases in this modern era. Various groups of drugs are used abiding the rationality. Recently, concerns have been broadening to include: Herbals, Traditional and complementary medicines, blood products, biologicals, medical devices, vaccines. ${ }^{2}$ The burden on public health of ADRs remains significant. Adverse reactions tend to be viewed, incorrectly, as 'side effects' and thus as distractions from patients' and doctors' priorities.

Excessive use of medications leads to adverse effects. Drug errors and ADRs in hospitalized and out-patients are well known, and contribute significantly to morbidity, mortality. Most are inevitable, and can be avoided. 
Pharmaco-economic research on the effects of adverse reactions show that governments spend large sums from health budgets to cover the resulting effects. In most countries the extent of this expenditure has not been measured. ${ }^{3}$ To make rational and judicious selection of drugs, it is important for the prescriber to get aware of the amount and commonness of possible undesirable risks.

Safety and efficacy are two parameters that influence the rationality of drug use. No drugs are devoid of side effects. To make a therapeutic agent more acceptable, three phases of clinical trial and lastly, very critical postmarketing surveillance is done. Based on clinical trial, some of these are rejected from the market, some are accepted for use. To provide safest drugs, larger target population with longer time is required. ${ }^{4}$ Pharmacovigilance aims at comparing the safety of various drugs, specifically recognizing the risk factors and leading to the evaluation of both the efficacy and the risk of pharmaceutical products. It provides timely communication and recommendations to regulatory authorities, clinicians, and conveying the selective information to users for ensuring the safe and the best use of medicines and monitoring the outcome of action previously undertaken. Pharmacovigilance is one of the essential components of patient care and the rational medication practice..$^{5}$ The major key of a successful pharmacovigilance relies on the involvement, understanding and reporting ADRs by all healthcare professionals including doctors, nurses, and pharmacists. The healthcare professionals must be aware of what to, how to and whom to report ADRs for the greater benefit of the patient. ${ }^{6}$ Recognition of less apparent adverse effects requires professional alertness, accurate evaluation and a knowledge of the causality assessment concepts.

Health care practitioners are more likely to recognize and record important ADRs if they trust their ability to detect, control and avoid these reactions. Local pharmacovigilance centers and educational facilities play vital role in this by promoting the implementation of pharmacovigilance standards and methods. 7 With a relatively high number of recent high-profile drug recalls, the issue of monitoring for ADR has been posed by both the pharmaceutical industry and numerous regulatory agencies worldwide. No degree of care and vigilance, as a medication is sold and administered to large populations, may guarantee full safety at the clinical trial level. Thanks to the fact that clinical trials include at most several thousand patients; less common side effects and ADR are still unknown before a medication reaches the market. Some very severe ADR, such as liver damage, are often undetected for small size of study populations.

Post-marketing pharmacovigilance uses methods like data mining and case reports analysis to classify the product interactions and ADR. It is the duty of the regulatory agencies to provide a well-established pharmacovigilance program for tracking ADR during the process of drug production and during the lifetime of a marketed drug. ${ }^{8}$ After the occurrence of Thalidomide catastrophe in 1961, WHO first established the pharmacovigilance program for international drug monitoring. Now, the WHO promotes this at the country level. More than 134 countries became part of this program now-a-days. ${ }^{9}$ The Uppsala Monitoring Centre (UMC) in Sweden maintains the international database of the ADR reporting.

More than 94 countries throughout the world were technically supported by the WHO-UMC located in Sweden. Neighbouring country, India established National Pharmacovigilance Program with the help from the World Bank on 2004, which was re-modelled in 2010 with the long-term goal to establish a "Centre of Excellence" through collaboration with the WHO and UMC. In the year2013, India's contribution to the WHOUppsala Monitoring Centre's global drug safety database (Vigibase) was $2 \% .{ }^{10}$ In England, USA and Germany, the prevalence rate of ADRs was $3.22 \%, 5.64 \%$ and $4.78 \%$ respectively. About $3.6 \%$ of all hospital admission were due to ADRs, of which $0.5 \%$ ended in fatality9. Around 80 percent of older people taking antipsychotic medications do not have dementia or other disorders that warrant the use of these potent drugs, and many of these patients experience significant side effects from medicines that have been mistakenly administered. Druginduced Parkinsonism has developed in 61,000 older adults also due to the use of other atypical or classical antipsychotic drugs such as haloperidol, chlorpromazine, thioridazine etc. ${ }^{11}$ Pharmacovigilance is proven to be an effective monitoring mechanism for the protection of medicines in a country with the assistance of the country's doctors, pharmacists, nurses and other health professionals to prevent any undue physical, mental and financial distress of patients. In 1996, a cell was established in Bangladesh to support WHO in DGDA. An ADR advisory committee (ADRAC) of 10 members had been created by the Ministry of Health and Family Welfare in 1997. The objective of this was to evaluate and propose how to solve problems of ADRs.

Bangladesh became the $120^{\text {th }}$ member country of WHO pharmacovigilance programs in December 2014, after reporting their $1^{\text {st }}$ adverse reaction case report to Vigibase through Vigiflow.10. To build community understanding, insight into the gaps in information, attitudes and practices regarding pharmacovigilance is necessary. A very few base line studies were done in the past in Bangladesh on pharmacovigilance comprising a mixed group or multiple groups of people.

The importance of pharmacovigilance is safety and monitoring of medicinal products, drug monitoring, pharmaceutical preparations, adverse effects, adverse drug reaction reporting, product surveillance, post marketing, legislation is utmost. Thus, this study was conducted to assess awareness of pharmacovigilance among doctors, interns, $5^{\text {th }}$ year students and stuff nurses 
and to evaluate the acquaintance, approach towards judicial reporting of ADRs and application (3A) of pharmacovigilance in Holy Family Red Crescent Medical College and Hospital, Dhaka, Bangladesh.

\section{METHODS}

The study design was qualitative with a mix of descriptive, cross sectional and exploratory research design tools. The descriptive study design helps the researcher to collect information on the current state of the phenomenon while the exploratory design familiarizes the researcher with basic data, settings and observations about the issue not yet studied.

The a pre-tested questionnaire composed of both quantitative and qualitative variables was developed from previous studies by Thangaraju et al, Datta $S$ et al and Ajoy et al validated through face and content validity techniques., ${ }^{2,4}$ The face validity was achieved by giving the draft questionnaire to a few of the respondents (interns, doctors, nurses) in Holy Family Red Crescent Medical College and Hospital to assess whether the response looks meaningful, well designed and basic concepts of the construct. Information gathered from this exercise was used to refine and modify the questionnaire further.

The content validity was done by two independent scholars from public health and pharmacology to assess its appropriateness, extent, clarity and relevance to the study. The incorporated draft questionnaire was recast for ambiguity. The reliability of the validated questionnaire was ascertained by test retest method. The questionnaire was tested twice at two weeks' interval on five respondents from October 2019 to November 2019 in the institute who were involved in healthcare services. The responses were compared and the reliability coefficient determined $(\mathrm{r}=0.85)$. Ethical considerations were fulfilled by obtaining verbal consent and maintaining the confidentiality.

The study participants were $5^{\text {th }}$ year medical students (66), interns (112), doctors of all faculties (90) and stuff nurses (149) in the hospital. Prior written informed consent was gathered from all participants explaining about the study and questionnaire, in brief. A sum total of 15 (nine related to acquaintance, two about approach and four related to application) validated and pretested $3 \mathrm{~A}$ questionnaire was designed to evaluate the knowledge (acquaintance with pharmacovigilance), attitude (approach towards pharmacovigilance) and their practice (application of ADR reporting). Total 417 questionnaires were distributed, of which 389 were returned and included in the study as valid and completed response. The study protocol was approved by the Institutional Ethical Review Committee (IERC) of Holy Family Red Crescent Medical College, Dhaka, Bangladesh.

\section{RESULTS}

Out of 417 questionnaires, 389 were satisfactorily filled and were included for statistical analysis. Thus, the response rate was $93.28 \%$. In the present study, a total of 389 health care professionals were assessed with 3A questionnaire about pharmacovigilance, of which males and females were $106(27.3 \%)$ and $283(72.7 \%)$, and the median age was 35.77 and 35.10 respectively. Among the respondents, $16.9 \%$ were $5^{\text {th }}$ year students with median age of 24.20 years, interns $27.5 \%$ with median age 28.09 , doctors $21.8 \%$ with median age 46.97 and nurses $33.6 \%$ with median age of 41.69 years as shown in Table 1.

Table 2 shows the details of the respondents' acquaintance with pharmacovigilance in nine questions and $78 \%$ of the nurses responded the right answers and doctors responded the lowest $29 \%$ on average. The average percentage of approach and application of pharmacovigilance was low in all the respondent groups. The poorest outcome was observed about reporting an ADR form by all respondents as $01 \%$ to $08 \%$.

Statistically significant difference was observed by analysing the mean score of the respondents of four groups on the acquaintance with pharmacovigilance domain with $\mathrm{p}=0.00281$ (significant at $\mathrm{p}<0.05$ ) as shown in Table 3.

The overall comparative status in figure 1 shows that the doctors have low acquaintance but moderate application of pharmacovigilance, whereas nurses have high responses on acquaintance and moderate in application. Lowest average (29\%) of acquaintance with pharmacovigilance was observed among doctor, approach was lowest.

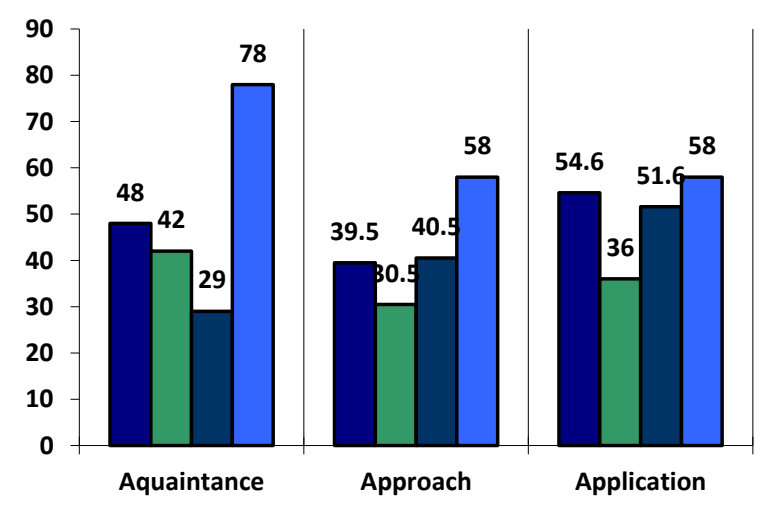

5th year alnterns aDoctors 口Nurses

Figure 1: Comparative status of $3 \mathrm{~A}$ of pharmacovigilance among different respondent groups. 
Table 1: Details of the respondents.

\begin{tabular}{|lllll|}
\hline Gender & $\mathbf{n = 3 8 9}$ & Frequency $(\%)$ & Median age (years) & IQR \\
\hline Male & 106 & 27.3 & 35.77 & 24 \\
\hline Female & 283 & 72.7 & 35.10 & 08 \\
\hline Respondents & & & & 09 \\
\hline Students & 66 & 16.9 & 24.20 & 22 \\
\hline Interns & 107 & 27.5 & 28.09 & 18 \\
\hline Doctors & 85 & 21.8 & 46.97 & \\
\hline Nurses & 131 & 33.6 & 41.69 & \\
\hline
\end{tabular}

Table 2: Percentage of correct answers of the respondents in different domains.

\begin{tabular}{|c|c|c|c|c|}
\hline Questions & $\begin{array}{l}\text { Students } \\
(\mathrm{n}=66) \\
(\%)\end{array}$ & $\begin{array}{l}\text { Interns } \\
(\mathrm{n}=107) \\
(\%)\end{array}$ & $\begin{array}{l}\text { Doctors } \\
(\mathrm{n}=\mathbf{8 5}) \\
(\%)\end{array}$ & $\begin{array}{l}\text { Nurses } \\
(\mathbf{n}=\mathbf{1 3 1}) \\
(\%)\end{array}$ \\
\hline \multicolumn{5}{|l|}{ Acquaintance with pharmacovigilance } \\
\hline Have you ever heard of pharmacovigilance? & 90 & 67 & 73 & 99 \\
\hline Do you know what to report & 54 & 35 & 32 & 93 \\
\hline Do you know how to report & 44 & 05 & 31 & 86 \\
\hline Do you know whom to report & 48 & 33 & 03 & 94 \\
\hline Is there any ADR monitoring center in your institution & 10 & 03 & 01 & 61 \\
\hline Is there any National PV guideline in BD & 45 & 42 & 21 & 83 \\
\hline Is there any International center for ADR monitoring & 51 & 66 & 23 & 94 \\
\hline What you understand about PV is, to assess medication? & 42 & 61 & 18 & 06 \\
\hline Who regulates the $P V$ in Bangladesh? & 48 & 74 & 67 & 88 \\
\hline Average percentage & 48 & 42.8 & 29 & 78 \\
\hline \multicolumn{5}{|l|}{ Approach to pharmacovigilance } \\
\hline Have you ever trained to report ADR form? & 04 & 01 & 01 & 20 \\
\hline Do you think ADR reporting is your professional obligation? & 75 & 60 & 80 & 96 \\
\hline Average percentage & 39.5 & 30.5 & 40.5 & 58 \\
\hline \multicolumn{5}{|l|}{ Application of pharmacovigilance } \\
\hline Do u know what is ADR reporting? & 69 & 44 & 56 & 86 \\
\hline Have you ever reported any ADR form? & 01 & 01 & 05 & 08 \\
\hline $\begin{array}{l}\text { Should pharmacovigilance be taught to every healthcare } \\
\text { professionals? }\end{array}$ & 94 & 63 & 94 & 80 \\
\hline Average percentage & 54.6 & 36 & 51.6 & 58 \\
\hline
\end{tabular}

Table 3: Average mean score of acquaintance in different groups.

\begin{tabular}{|llllll|}
\hline Variables & Students & Interns & Doctors & Nurses & Total \\
\hline $\mathbf{\Sigma}$ & 432 & 386 & 269 & 704 & 1791 \\
\hline Mean & 48 & 42.88 & 29.88 & 78.22 & 49.75 \\
\hline $\mathbf{\Sigma} \mathbf{x}^{\mathbf{2}}$ & 24050 & 22154 & 13107 & 61908 & 121219 \\
\hline SD & 20.3531 & 26.4549 & 25.1667 & 29.2394 & 30.2923 \\
\hline Statistical analysis & & & & & Inference \\
\hline Different groups & SS & Df & MS & The f-ratio=5.78817, p=0.002801 \\
\hline Between groups & 11297.4167 & 3 & 3765.8056 & The result is significant at $\mathrm{p}<0.05$ \\
\hline Within groups & 20819.3333 & 32 & 650.6042 & \\
\hline Total & 32116.75 & 35 & & & \\
\hline
\end{tabular}

\section{DISCUSSION}

Pharmacovigilance is a major and inseparable part of clinical research. The core principle is formed by vast knowledge of adverse effects. So far, we found, this is the first study involving the different levels of respondents related to healthcare service in a tertiary care teaching hospital in Bangladesh, as it included medical students, interns, doctors and nurses altogether in same set of questionnaires. The foremost thing to be noted in these types of studies is the response of the participants. 
Few previous studies on knowledge, attitude and practice had reported a response rate of $55.33 \%, 61 \%$ and $83.5 \%$ among the healthcare professionals in India. ${ }^{12,13}$ In this study, the rate of overall response was $93.28 \%$ in the tertiary care teaching hospital, which is a good sign and reflection of the keenness among the respondents which is comparable to other similar studies as Pimpalkhute et al and Ajay et al reported the response rate of $93.33 \%$ and $83.5 \%$ respectively. ${ }^{14,6}$ On the other hand response rate were much less in studies done by Gupta et al $(67.33 \%)$ and Hema et al (70\%). ${ }^{15,16}$ This high rate of response in present study might be due to inclusion of the 5th year medical students who tends to be more aware about pharmacovigilance.

The acquaintance level with pharmacovigilance was found to be poor in this study. Only $29 \%$ of the doctors were found to have overall knowledge of pharmacovigilance, whereas $78 \%$ of nurses showed better acquaintance with the knowledge. The overall level of knowledge was good in nurses. Whereas relatively poor in $5^{\text {th }}$ year students, less in interns and poor in doctors.

In case of $5^{\text {th }}$ year students, they are taught ins and out about pharmacovigilance in Pharmacology lectures and tutorial classes, so their response is relatively good. On the other hand, interns almost forgot about theoretical knowledge of pharmacovigilance, and due to underreporting of ADRs, their knowledge gets poorer. In doctors due to lack of practice and not attending CME and workshops and of course owing to their reluctant attitude, their performance was the poorest. Similarly, a study conducted by Dikshit et al. reported that $70 \%$ of the respondents were unaware of where to report. ${ }^{17}$ In this study most of the respondents don't know what to report, how to report and whom to report. In another study done by Bepari et al showed that higher number of the respondents do not know what to report and whom to report. ${ }^{18}$ The present study revealed that students, interns and doctors were unaware of ADR monitoring center of their respective institution.

As a medication is sold and administered to large populations, no defined level of care and vigilance can guarantee full safety at the pre-clinical and clinical test levels. Thanks to the fact that clinical trials include at most several thousand patients; uncommon side effects and ADRs are still unknown before a medication reaches the market. Also, very serious ADR, such as damage to the liver, are often undetected as the sample population is limited.

It is the immense responsibility of doctors, nurse, pharmacist, interns, post-graduate, even the patients to report ADRs. But unfortunately, Bangladesh is lacking the formal targeted teaching and training to detect and report ADRs as well as no research to monitor ADRs among health professionals.

In this context, to increase the overall awareness about pharmacovigilance, educational intervention may play a vital role for acquaintance with pharmacovigilance by attending educational workshops, CME's (continuous medical education), seminars and clinical meetings at on regular basis. ${ }^{19}$ The task of pharmacovigilance centers is intended to enhance the capacity of national pharmacovigilance centers (PVCs) to detect, evaluate and provide recommendations for preventing or minimizing patient-damaging medication errors. This is also intended to model collaboration between national pharmacovigilance centers and patient safety organizations (PSOs) to coordinate together to mitigate preventable medicinal harms.

\section{CONCLUSION}

Academic knowledge of pharmacovigilance, the national pharmacovigilance program and its activities should be given more weightage in undergraduate and postgraduate curriculum to be acquainted with pharmacovigilance at student level. Visiting the pharmacovigilance centers during training, the hands-on reporting of ADRs can be much helpful to sensitize the doctors to feel comfortable with the approach and application of pharmacovigilance in practice.

\section{ACKNOWLEDGEMENTS}

Author would like to thank all the respondents including the $5^{\text {th }}$ year students $(\mathrm{HF}-17)$ for their voluntary participation in the study. Also extend gratitude and thanks to all the faculty staff including Dr. Khandaker Abu Talha and Dr. Mithila Ahmed for their extended cooperation and support.

Funding: No funding sources Conflict of interest: None declared

Ethical approval: The study was approved by the Institutional Ethics Committee

\section{REFERENCES}

1. World Health Organization. Committee of Experts on Management of Safety and Quality in Health Care (SP SQS) Expert Group on Safe Medication Practices. Glossary of Terms Related to Patient and Medication Safety: World Health Organization; Available at: https://www.who.int/patientsafety/ highlights/COE_patient_and_medication_safety_gl.p df. $2005 ; 13$.

2. Thangaraju $\mathrm{P}$, Venkatesan $\mathrm{S}$, Tamilselvan $\mathrm{T}$, Sivashanmugam E, Showkath Ali MK. Evaluation of awareness about pharmacovigilance and adverse drug reaction monitoring among medical professionals attending Central Leprosy Institute. Mustansiriya Med J. 2018;17:63-8.

3. World Health Organization. The importance of pharmacovigilance. 2002. Accessed in: https://apps.who.int/iris/bitstream/handle/10665/424 93/a75646.pdf. Accessed on 20/08/2020. 
4. Datta S, Sengupta S. An evaluation of knowledge, attitude, and practice of adverse drug reaction reporting in a tertiary care teaching hospital of Sikkim. Perspectives in clinical research. 2015;6(4):200-6.

5. World Health Organization. The Safety of Medicines in Public Health Programmes Pharmacovigilance an Essential Tool. Geneva: World Health Organization; 2006. Available from: http:// www.who.int/medicines/areas/quality_safety/safety_ efficacy/ Pharmacovigilance_B.pdf. Accessed on 20/08/2020.

6. Ajoy B, Bezbaruah B, Swapnanil G. Knowledge, Attitude and Practices of Pharmacovigilance among junior doctors of a tertiary health care institute in North East India. J Appl Med Sci. 2016;4(9A):324853.

7. Meyboom RHB, Hekster YA, Egberts ACG, Gribnau FWJ, Edwards IR. Casual or Causal? The role of causality assessment in pharmacovigilance. Drug Safety. 1997; 16:374-89

8. Craven BM, Stewart GT, Khan M. Chan TYK. Monitoring the safety of herbal medicines. Drug Safety. 1997;17(4):209-15.

9. Dharman D, Krishnan P, Ravikumar KG, Dharan SS, Rajan S. The era of pharmacovigilance and the need of pharmacovigilance in psychiatry: A review. J Drug Delive Therap. 2019; 9(1):449-52.

10. Central Drugs Standard Control Organization. Long Term Objective of Pharmacovigilance Programme in India. Available from: http://www.cdsco.nic.in/ pharmacovigilance_intro.htm. Accessed on 20/08/2020.

11. Md Al-Mustansir, Saha D, Paul S, Rahim ZB, Hosen SMZ. Studies on Pharmacovigilance in Bangladesh: Safety Issues. IJPTP. 2013;4(2):613-21.

12. Karelia BN, Piparava KG; Knowledge, attitude and practice of pharmacovigilance among private healthcare professionals of Rajkot city. Int J Basic Clin Pharmacol, 2014;3:50-3.

13. Hardeep, Bajaj JK, Rakesh K. A Survey on the Knowledge, Attitude and the Practice of
Pharmacovigilance Among the Health Care Professionals in a Teaching Hospital in Northern India. J Clin Diagn Researc. 2013;7:97-9.

14. Pimpalkhute SA, Jaiswal KM, Sontakke SD, Bajait CS, Gaikwad A. Evaluation of awareness about pharmacovigilance and adverse drug reaction monitoring in resident doctors of a tertiary care teaching hospital. Indian J Med Sci. 2012;66(34):55-61.

15. Gupta SK, Nayak RP, Shivaranjani R, Vidyarthi SK. A questionnaire study on the knowledge, attitude and practice of pharmacovigilance among the healthcare professionals in a teaching hospital in South India. Perspect Clin Research. 2015;6(1):45-52.

16. Hema NG, Bhuvana KB. Pharmacovigilance: the extent of awareness among the final year students, interns and postgraduates in a government teaching hospital Sangeetha. J Clin Diag Res. 2012;6(7):124853.

17. Dikshit RK, Desai C, Desai MK. Pleasures and pains of running a pharmacovigilance center. Indian $\mathbf{J}$ Pharmacol. 2008;40(1):S31-4.

18. Bepari A, Niazi SK, Rahman I, Dervesh AM. The comparative evaluation of knowledge, attitude, and practice of different health-care professionals about the pharmacovigilance system of India. $\mathbf{J} \mathrm{Adv}$ Pharmac Technol Res. 2019;10(2):68-74.

19. Tabali M, Jeschke E, Bockelbrick A, Witt MC, Willich SN, Ostermann $\mathrm{T}$ et al. Educational intervention to improve physician reporting of adverse drug reactions (ADRs) in a primary care setting in complementary and alternative medicine. BMC Public Health 2009;9:274.

Cite this article as: Nasir M, Zahan T, Farha N, Chowdhury ASM S. Acquaintance, approach and application of pharmacovigilance: questionnaire based study at a tertiary care teaching hospital in Dhaka. Int J Basic Clin Pharmacol 2020;9:1497-502. 